\title{
Recovery of renal tubule phosphate reabsorption despite reduced levels of sodium-phosphate transporter
}

\author{
Michael M Friedlaender ${ }^{1}$, Hanna Wald ${ }^{1}$, Michal Dranitzky-Elhalel ${ }^{1}$, Moshe Levi ${ }^{2}$ and Mordecai M Popovtzer ${ }^{1,2}$ \\ ${ }^{1}$ Nephrology and Hypertension Services, Hadassah University Hospital, Jerusalem, Israel 91120 and ${ }^{2}$ Departments of Medicine, Biophysics and \\ Physiology, Division of Renal Diseases and Hypertension, University of Colorado Health Sciences Center and Veterans Administration Medical Center, \\ 4200 East 9th Avenue, Denver, CO 80262, USA \\ (Correspondence should be addressed to M M Popovtzer; Email: mpopovtzer@hotmail.com)
}

\begin{abstract}
Background: The acute effect of parathyroid hormone (PTH) on phosphate transport has been reported to be mediated by rapid downregulation of sodium-phosphate transporter (NaPi-IIa) protein, but the association was observed with pharmacological doses of PTH.

Objective: To explore the effects of physiological doses of PTH on NaPi-IIa protein and its relationship to phosphate transport.

Methods: Acute clearance studies were performed in parathyroidectomized rats given a bolus i.v. physiological dose $(1 \mu \mathrm{g})$ of bovine PTH$(1-34)$ and NaPi-IIa protein concentrations were examined at different time intervals.

Results: Fractional excretion of phosphate increased from $0.031 \pm 0.006$ (mean \pm s.e.) to $0.238 \pm 0.059(P<0.01$ compared with baseline and compared with controls $)$ at $40 \mathrm{~min}$ and returned to control values by $120 \mathrm{~min}$. Urinary cAMP concentrations were increased at $20 \mathrm{~min}$ only. Superficial cortex brush-border membrane (BBM) NaPi-IIa protein was decreased from baseline at both 40 and $120 \mathrm{~min}(P<0.01)$ and did not recover at $240 \mathrm{~min}(P<0.01$ compared with baseline and compared with controls).

Conclusion: These results confirm that PTH, even in physiological dosage, causes a rapid decrease in BBM NaPi-IIa, but subsequent recovery of phosphate reabsorption is poorly correlated with BBM concentrations of NaPi-IIa protein. This suggests that transport mechanisms other than NaPi-IIa are important in renal phosphate reabsorption.
\end{abstract}

European Journal of Endocrinology 151 797-801

\section{Introduction}

Renal proximal tubular epithelial cells express a brush border associated type IIa sodium-phosphate cotransporter (NaPi-IIa). This has been found to be the major mediator of renal phosphate reabsorption (1). Mice deficient in the NaPi-IIa gene exhibit 20-30\% cotransporter activity as compared with wild-type animals (2). Rapid downregulation of NaPi-IIa occurs during treatment with parathyroid hormone (PTH) as a result of cellular internalization of the NaPi-IIa protein from the apical membrane to endocytoplasmic vesicles (3). Subsequent degradation of the protein occurs in lysosomes (4). The latter is dependent on microtubule integrity (5). PTH-induced NaPi-IIa endocytosis can be observed within minutes (6), whereas lysosomal degradation of NaPi-IIa may take 3-4h (7). It should also be noted that pharmacological doses of PTH were used in the in vivo experiments referred to here $(1,4-6)$. Rapid increase $(2 \mathrm{~h})$ in renal brush-border membrane (BBM) NaPi-IIa after dietary restriction of phosphate appears to occur independently of de novo protein synthesis and is also dependent on microtubule integrity (8). Full recovery of sodium-phosphate transport after exposure of OK cells to PTH takes 5-7 h (9). This can be blocked by cycloheximide, but not by actinomycin D, suggesting the need for post-translational protein synthesis. However, the in vivo phosphaturic effects of physiological doses of PTH are transient and, to our knowledge, BBM concentrations of NaPi-IIa protein after cessation of PTH treatment in vivo have not been studied.

We therefore studied the effect of bolus injection of a physiological dose of PTH in parathyroidectomized rats undergoing acute clearance experiments and examined the changes in superficial renal cortex BBM NaPi-IIa protein. We observed that the suppressed rate of tubular phosphate reabsorption returned to normal despite continued reduced BBM NaPi-IIa protein content. 


\section{Methods}

\section{Animal models}

Lightly anaesthetized, parathyroidectomized, white male Sabra rats, weighing 200-240g and receiving Purina chow $(0.67 \%$ phosphorus, $0.97 \%$ calcium $)$ and with tap water available ad libitum underwent acute clearance experiments after catheterization of femoral vessels and the urinary bladder. Rats' kidneys were removed rapidly at the end of the experiments for preparation of superficial cortex BBMs. Parathyroidectomy (PTX) was performed by electric cauterization with the animal under light ether anaesthesia, 2 days before the studies.

\section{Clearance studies}

Clearance studies were performed between $0800 \mathrm{~h}$ and $1400 \mathrm{~h}$ with the animal under intraperitoneal pentobarbitone sodium ( $40 \mathrm{mg} / \mathrm{kg}$ body weight) anaesthesia. In brief, animals were infused i.v. with $0.18 \%$ sodium chloride and $4.3 \%$ dextrose in water at a rate of $1.5 \mathrm{ml} / 100 \mathrm{~g}$ body weight. After a 60-min equilibration period, a 20-min baseline urine collection was made. A single i.v. bolus of $1 \mu \mathrm{g}$ bovine PTH(1-34) (Sigma Chemical Co.) was given to each rat. To prevent binding of the PTH to glassware (10), the PTH was first added to $0.25 \mathrm{ml}$ PTX rat serum. Control animals received vehicle only. Subsequently, urine samples were collected under ice cooling, at 20-min intervals. Blood samples were taken after the initial baseline urine collection, when volume was replaced with $0.9 \%$ sodium chloride solution, and at the end of the experiment.

\section{Sample analysis}

Blood and urine samples were assayed spectrophotometrically for creatinine, calcium and phosphorus using a computer-directed analyser (Cobras Mira, Roche). Urinary CAMP was measured in duplicate by the proteinbinding assay of Gilman (11), using a RIA $\left[{ }^{3} \mathrm{H}\right] \mathrm{cAMP}$ assay kit (Amersham).

\section{Isolation of BBMs}

Kidneys were rapidly removed and slices were cut from the superficial cortex at $4^{\circ} \mathrm{C}$, homogenized in buffer consisting of $300 \mathrm{mmol} / \mathrm{l}$ DL mannitol, $5 \mathrm{mmol} / \mathrm{l}$ EGTA, $16 \mathrm{mmol} / \mathrm{l}$ Hepes and Tris $\mathrm{pH} 7.5$ containing protease inhibitor cocktail tablets (Boehringer Mannheim $\mathrm{GmbH}$ ). BBMs were precipitated from this homogenate by double $\mathrm{Mg}^{2+}$ precipitation and differential centrifugation as described previously (12). The final pellet was resuspended in the same buffer as above. Protein concentration of the BBM preparation was determined by an automated pyrogallol red calori- metric method (Cobras Mira) and equal amounts of protein $(60 \mu \mathrm{g})$ were added to each lane of the polyacrylamide gels.

\section{SDS-PAGE immunoblotting}

Aliquots of BBM were denaturated 1:1 with sample buffer containing 4\% SDS, $20 \%$ glycerol, $1 \% \beta$-mercaptoethanol and $125 \mathrm{mmol} / \mathrm{l}$ Tris $-\mathrm{HCl}, \mathrm{pH}$ 6.8. Sixty micrograms BBM protein per lane were separated on $10 \%$ polyacrylamide gels and electrotransferred to nitrocellulose paper. Protein loading equality between the lanes was confirmed before chemiluminescence examination by staining with Ponceau S stain. After blockade with $5 \%$ fat-free milk powder, western blots were performed with antiserum against the C-terminal amino acid sequence of NaPi-IIa at a dilution of 1:5000 $(1,13)$. Secondary antibody was goat anti-rabbit IgG at a dilution of 1:10 000. Antibody binding was visualized using enhanced chemiluminescence; densitometry was performed in a Phosphor Imager.

\section{Statistics}

Results are presented as means \pm s.E. Analysis of variance was performed for statistical evaluation between different groups. Results between individual groups were compared by a non-paired Student's $t$-test with a modified level of significance according to the Bonferroni method (14).

\section{Results}

\section{Effects of PTH on serum chemistries}

Laboratory data of the PTX rats are shown in Table 1. There were no significant differences in serum creatinine, calcium or phosphate between the PTH-treated PTX animals and control PTX animals, both at baseline and when the animals were killed. Body weight and creatinine clearance were insignificantly greater in control animals.

\section{Effects of PTH on fractional excretion of phosphate}

Fractional excretion of phosphate is shown in Fig. 1. This was maximal at $40 \mathrm{~min}$ in PTH-treated animals and thereafter decreased rapidly, albeit remaining significantly greater than in control animals up to $100 \mathrm{~min}$. It should be noted that the rapid decrease in fractional excretion of phosphate after 40 min indicates recovery of renal phosphate reabsorption. This recovery was almost complete at $120 \mathrm{~min}$, and was also evident at 180 and $240 \mathrm{~min}$. 
Table 1 Laboratory data.

\begin{tabular}{|c|c|c|c|c|c|}
\hline & $\begin{array}{l}\text { Weight } \\
\text { (g) }\end{array}$ & $\begin{array}{l}\text { Serum creatinine } \\
(\mu \mathrm{mol} / \mathrm{l})\end{array}$ & $\begin{array}{l}\text { Serum calcium } \\
(\mathrm{mEq} / \mathrm{l})\end{array}$ & $\begin{array}{l}\text { Serum phosphate } \\
(\mathrm{mmol} / \mathrm{l})\end{array}$ & $\begin{array}{l}\text { Creatinine clearance } \\
\qquad(\mathrm{ml} / \mathrm{min})\end{array}$ \\
\hline \multicolumn{6}{|c|}{ PTX rats receiving PTH } \\
\hline Baseline $(n=15)$ & $225 \pm 8.3$ & $37.7 \pm 0.58$ & $3.28 \pm 0.14$ & $3.55 \pm 0.10$ & $1.06 \pm 0.09$ \\
\hline \multicolumn{6}{|l|}{ At harvesting } \\
\hline $40 \min (n=3)$ & $240 \pm 20.8$ & $36.1 \pm 2.3$ & $3.57 \pm 0.39$ & $3.67 \pm 0.26$ & $1.07 \pm 0.19$ \\
\hline $120 \min (n=8)$ & $236 \pm 20.8$ & $37.4 \pm 2.74$ & $3.33 \pm 0.15$ & $3.56 \pm 0.09$ & $1.02 \pm 0.06$ \\
\hline $240 \min (n=4)$ & $222 \pm 2.5$ & $40.1 \pm 2.4$ & $3.07 \pm 0.09$ & $3.50 \pm 0.15$ & $0.96 \pm 0.05$ \\
\hline \multicolumn{6}{|l|}{ Control PTX rats } \\
\hline Baseline $(n=9)$ & $245 \pm 7.4$ & $39.1 \pm 1.6$ & $3.52 \pm 0.07$ & $3.58 \pm 0.13$ & $1.26 \pm 0.12$ \\
\hline \multicolumn{6}{|l|}{ At harvesting } \\
\hline $120 \min (n=4)$ & $235 \pm 5.5$ & $38.5 \pm 2.4$ & $3.31 \pm 0.16$ & $3.15 \pm 0.09$ & $1.32 \pm 0.10$ \\
\hline
\end{tabular}

\section{Effects of PTH on urinary cAMP}

Figure 2 shows that urinary cAMP excretion peaked at 20 min after PTH injection and had returned to baseline at $40 \mathrm{~min}$.

\section{Effects of PTH on BBM NaPi-IIa protein abundance}

Despite the recovery in tubular reabsorption of phosphate, it can be seen in Fig. 3 that BBM NaPi-IIa protein concentrations, which were significantly reduced at $40 \mathrm{~min}$, had not recovered at 120 or at $240 \mathrm{~min}$ after the PTH injection, despite full recovery of renal tubular phosphate reabsorption as seen in Fig. 1. Figure 4 shows representative gels from the experiments, showing reduced $\mathrm{NaPi}$-IIa protein at both $40 \mathrm{~min}$ and 120 min after the injection of PTH (Fig. 4A), and that the decrease in $\mathrm{NaPi}$-IIa protein was still present at 240 min after PTH injection (Fig. 4B).

\section{Discussion}

Tubular epithelial phosphate transport is currently believed to be regulated mainly by the type IIa

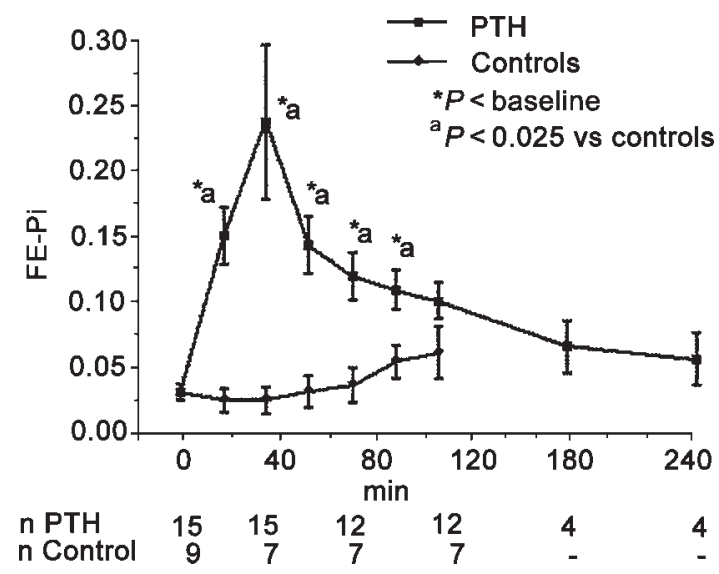

Figure 1 Fractional excretion of phosphorus (FE-Pi) in PTX rats at baseline $(0 \mathrm{~min})$ and after bolus i.v. injection of PTH $(1 \mu \mathrm{g})$. Control rats received vehicle only. sodium-phosphate transporter. Renal expression of NaPi-IIa mRNA and NaPi-IIa protein content in epithelial cell BBMs are markedly influenced by dietary phosphate intake (15). Furthermore, the phosphaturic influence of PTH has been shown to be modulated by cellular internalization of the NaPi-IIa protein from the BBMs, followed by lysosomal degradation $(1,3-8)$.

We and others have recently noted that BBM expression of NaPi-IIa is not always well correlated with changes in phosphate transport (16-18). It was suggested that the action of PTH may involve changes in NaPi-IIa activity or in the activity or availability of other transporters that influence phosphate transport. In the present study, tubular phosphate reabsorption was acutely inhibited by bolus injection of PTH, which caused an acute and significant decrease in BBM NaPi-IIa protein content. However, the tubular reabsorption of phosphate recovered within $2 \mathrm{~h}$ at a time when BBM NaPi-IIa protein content remained acutely reduced. Thus, while confirming that PTH acutely decreases BBM NaPi-IIa protein content even when given in a physiological dose, the findings of our study suggest that the BBM NaPi-IIa protein concentrations are poorly correlated with the subsequent recovery of tubular phosphate transport after an acute bolus injection of PTH. The explanation for this finding may be that the BBM may be contaminated

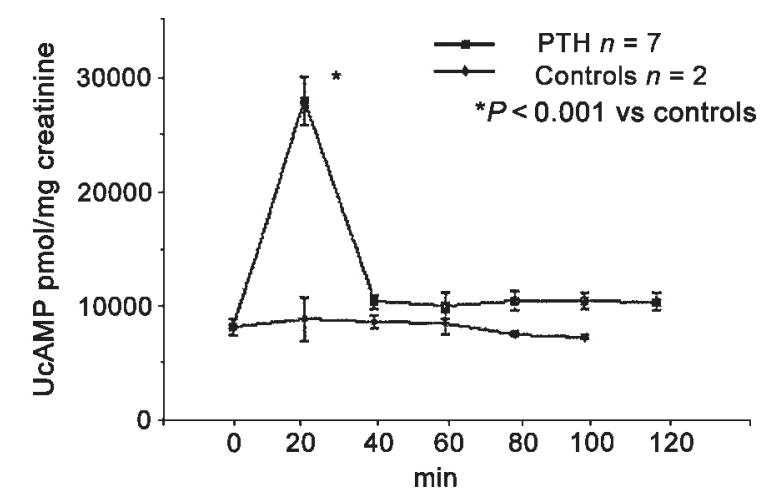

Figure 2 Urinary cAMP (UcAMP) excretion in rats treated as in Fig. 1. 
${ }^{*} P<0.01$ vs baseline and controls $120 \mathrm{~min}$

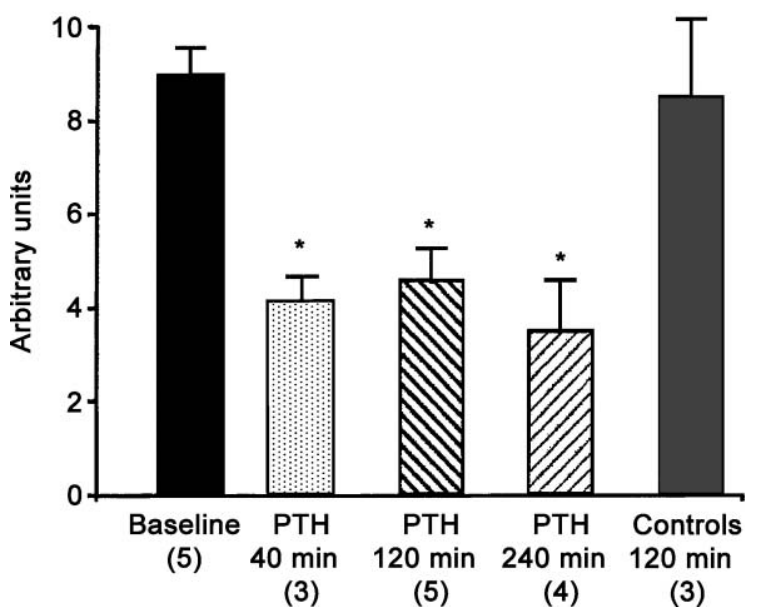

Figure 3 Superficial cortex BBM NaPi-Ila protein concentrations (arbitrary densitometry units) in rats treated as in Fig. 1. Numbers in parentheses are number of rats.

(A)

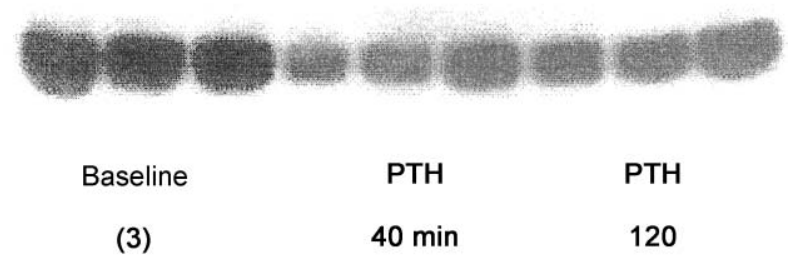

(3)

$\min$

(3)

(B)

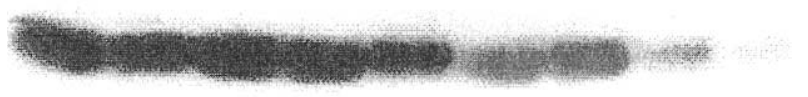

Baseline

Control

PTH 240

(2)

$120 \min$

$\min$

(3)

(4)

Figure 4 Representative gels showing NaPi-lla protein at both 40 and $120 \mathrm{~min}$ after the injection of PTH (A), and the decrease in Napi-Ila still present at 240 min after PTH injection (B). Numbers in parentheses are number of rats.

with vesicles in the endocytosis or exocytosis pathway, that the activity of the NaPi-IIa transporter remaining in the BBM is increased in this situation, that there may be increased renal tubular phosphate reabsorption at tubular sites other than the proximal tubule, or that other sodium-phosphate cotransport proteins that are important for phosphate reabsorption may be activated.
Regarding the first possibility, although we can not rule out for certain that the BBM may be contaminated with vesicles in the endocytosis or exocytosis pathway, western blot studies with isolated BBM have not shown this to be the case.

Regarding the possibility that other sodium-phosphate cotransport proteins that are important for phosphate reabsorption may be activated, in addition to the predominant type IIa sodium-phosphate cotransporter, type IIc, type I and type III sodiumphosphate cotransporters are also expressed in the kidney. In quantitative terms, of the total renal sodium-phosphate cotransporter mRNAs, type I accounts for $15 \%$, type II for $84 \%$ and type III for $0.5 \%$ (19). NaPi-Ia is expressed in BBMs of both the proximal and the distal tubules. $\mathrm{NaPi}-\mathrm{Ib}$ is expressed in brain and in erythrocytes. NaPi-Ia mediates sodium-phosphate transport when expressed in Xenopus laevis oocytes and is PTH-insensitive. It also operates as a chloride channel and mediates the transport of organic anions $(20,21)$. Type III cotransporters are cell-surface retroviral receptors, Glvr and ram (Pit 1 and Pit 2). They display widespread renal and extrarenal expression. Type III mRNA is expressed along the entire nephron. It has been proposed that they mediate basolateral phosphate uptake to support cellular energy metabolism. In this regard, they may be viewed as fulfilling a housekeeping function (22). $\mathrm{NaPi}$-IIc, a second renal $\mathrm{NaPi}$-II-related isoform, has been reported in rats and humans. It is predominantly expressed in weaning rats and is expressed much less in adult animals (23). It has a high affinity for phosphate, is regulated by dietary phosphate and functions as a major sodium-phosphate cotransporter in rapidly growing weaning rats. Its role is reduced in adult animals, in which NaPi-IIa is the major regulated sodium-phosphate cotransporter. NaPi-IIc exhibits homology with NaPi-IIa and colocalizes with it exclusively in the proximal tubular BBM. NaPi-IIb is expressed in small intestine, in lung, in prostate, in pancreas and in salivary glands, but not in the mammalian kidney (24). Hybrid depletion studies suggested that $\mathrm{NaPi}$-IIc accounts for $30 \%$ of sodium-phosphate cotransporters in the kidneys of phosphate-deprived adult mice (21). NaPi-IIc protein is maximally upregulated in $\mathrm{NaPi}$-IIa knockout mice and therefore is a candidate for residual sodium-phosphate cotransport in BBMs of NaPi-IIa knockout mice. Its protein abundance is 2.7-fold greater in NaPi-IIa knockout mice than in wild-type littermates $(21,22)$.

Our present observation of recovery of renal phosphate reabsorption despite reduced $\mathrm{NaPi}$-IIa protein concentrations remains unexplained. Further studies are required to explore the possibility that upregulation of other sodium-phosphate cotransporters, including NaPi-IIc, as discussed above and as has been reported in NaPi-IIa knockout mice, could account for the present findings. 


\section{Acknowledgements}

This study was supported by grants from VA Merit Review and NIH (M L) and Hadassah University Hospital (M M P). The authors acknowledge expert assistance by Susan DeGrange and Jacklyn Martinez in preparation of this manuscript.

\section{References}

1 Kempson SA, Lotscher M, Kaissling B, Biber J, Murer H \& Levi M. Parathyroid hormone action on phosphate transporter mRNA and rat proximal tubules. American Journal of Physiology 1995 $268784-891$.

2 Beck L, Karaplis AC, Amizuka N, Hewson AS, Ozawa H \& Tenenhouse HS. Targeted inactivation of Npt2 in mice leads to severe renal phosphate wasting, hypercalciuria and skeletal abnormalities. PNAS 199895 5372-5377.

3 Pfister MF, Lederer E, Forgo J, Zeigler U, Lotscher M, Quabius ES, Biber J \& Murer H. Parathyroid hormone-dependent degradation of type II Na $+/ \mathrm{Pi}$ cotransporters. Journal of Biological Chemistry 2012272 20125-20130.

4 Keusch I, Traebert M, Lotscher M, Kaissling B, Murer H \& Biber J. Parathyroid hormone and dietary phosphate provoke a lysosomal routing of the proximal tubular $\mathrm{Na} / \mathrm{Pi}$-cotransporter type II. Kidney International $1998 \mathbf{5 4} 1224-1232$.

5 Lotscher M, Scarpetta Y, Levi M, Halaihel N, Wang H, Zajicek HK, Biber J, Murer H \& Kaissling B. Rapid downregulation of rat renal $\mathrm{Na} / \mathrm{Pi}$ cotransporter in response to parathyroid hormone involves microtubule rearrangement. Journal of Clinical Investigation 1999 $104483-494$

6 Traebert M, Roth J, Biber J, Murer H \& Kaissling B. Internalization of proximal tubular type II Na-Pi cotransporter by PTH: immunogold electron microscopy. American Journal of Physiology: Renal Physiology 2000278 F148-F154.

7 Pfister MF, Ruf I, Strange G, Ziegler U, Lederer E, Biber J \& Murer H. Parathyroid hormone leads to the lysosomal degradation of the renal type II Na/Pi cotransporter. PNAS 199895 1909-1914.

8 Lotscher M, Kaissling B, Biber J, Murer H \& Levi M. Role of microtubules in the rapid regulation of renal phosphate transport in response to acute alterations in dietary phosphate content. Journal of Clinical Investigation 199799 1302-1312.

9 Malmstrom K \& Murer H. Parathyroid hormone regulates phosphate transport in OK cells via an irreversible inactivation of a membrane protein. Federation of European Biochemical Societies Letters $1987216257-260$.

10 Burnatowska MA, Harris CA, Sutton RAL \& Seeley JF. Effects of vitamin D on renal handling of calcium, magnesium and phosphate in the hamster. Kidney International 198727 864-870.

11 Gilman AG. A protein-binding assay for adenosine 3/5-cyclic monophosphate. PNAS 197067 305-312.
12 Levi M, Baird BM \& Wilson PV. Cholesterol modulates rat renal brush border membrane phosphate transport. Journal of Clinical Investigation 199085 231-237.

13 Levi M, Shayman JA, Abe A, Gross SK, McCluer RH, Biber J, Murer H, Lotscher M \& Cronin RE. Dexamethasone modulates rat renal brush border membranes phosphate transporter mRNA and protein abundance and glycolipid composition. Journal of Clinical Investigation $199596207-216$.

14 Godfrey K. Comparing the means of several groups. New England Journal of Medicine 1985131 1450-1456.

15 Murer H, Forster I, Hernando N, Lambert G, Traebert M \& Biber J. Posttranscriptional regulation of the proximal tubule transporter in response to PTH and dietary Pi. American Journal of Physiology: Renal Physiology 1999277 F676-F684.

16 Friedlander MM, Wald H, Dranitzky-Elhalel M, Zajicek HK, Levi M \& Popovtzer MM. Vitamin D reduces Na phosphate transporter $(\mathrm{NaPi}-2)$ in PTH-infused rats: vitamin $\mathrm{D}$ effects on renal $\mathrm{Pi}$ handling. American Journal of Renal Physiology 2001281 428-433.

17 Lederer ED, Sohi SS \& Mcleish KR. Parathyroid hormone stimulates extracellular signal-regulated kinase (ERK) activity through two independent transduction pathways: role of ERK in sodiumphosphate cotransport. Journal of the American Society of Nephrology $200011222-231$

18 Zajicek H, Wang H, Puttaparthi K, Halaihel N, Markovich D, Shayman J, Beliveau R, Wilson P, Rogers T \& Levi M. Glycosphingolipids modulate renal phosphate transport in potassium deficiency. Kidney International $200160694-704$.

19 Murer H, Hernando N, Forster I \& Biber J. Regulation of Na/Pi transporters in the proximal tubules. Annual Review of Physiology $200365531-542$.

20 Peerce BE, Peerce B \& Clarke R. Phosphophloretin sensitivity of rabbit renal NaPi-IIa and NaPi-Ia. American Journal of Physiology: Renal Physiology 2004286 F955-F964.

21 Tenenhouse H, Martel J, Gauthier C, Segawa H \& Miyamoto K. Differential effect of Npt2a gene ablation and X linked Hyp mutation on renal expression Npt2c. American Journal of Physiology: Renal Physiology 2003285 F271-F1278.

22 Tenenhouse HS \& Murer H. Disorders of renal tubular phosphate transport. Journal of the American Society of Nephrology $2003 \mathbf{1 4}$ $240-247$.

23 Segawa H, Kaneko I, Takahashi A, Kuwahata M, Ito M, Ohkido I, Tatsumi S \& Miyamoto K. Growth related renal type II Na/Pi cotransporter. Journal of Biological Chemistry $2002 \quad \mathbf{2 7 7}$ 19665-19672.

24 Werner A \& Kinne RKH. Evolution of Na-Pi systems. American Journal of Physiology: Regulatory, Integrative and Comparative Physiology 2001280 R301-R312.

Received 12 February 2004

Accepted 6 September 2004 